\title{
Autonomía y movimientos sociales. La Liga de Campesinos Pobres y la izquierda chilena (1935-1942)
}

\author{
Autonomy and social movements. \\ Poor Peasants League and the Chilean Left (1935-1942)
}

Nicolás Acevedo Arriaza

\begin{abstract}
Resumen
El siguiente artículo revisa la formación y disolución de la Liga de Defensa de Campesinos Pobres, la primera organización campesina en Chile, con cobertura nacional. El texto relaciona sus debilidades en torno al nivel de dependencia y escasa autonomía del movimiento social con respecto a los partidos políticos y las instituciones estatales, tendencia que fue hegemónica en el desarrollo del movimiento popular entre 1932-1973.
\end{abstract}

Palabras Clave: Movimiento Campesino- Izquierda chilena Sindicalización Campesina- Reforma Agraria- Pequeños Agricultores.

\begin{abstract}
The article reviews the formation and dissolution of the League for the Defense of Poor Farmers, the first peasant organization in Chile, nationwide. The text relates weaknesses around the level of dependence and lack of autonomy of the social movement with respect to political parties and state institutions, a trend that was hegemonic in the development of the popular movement between 1932-1973.
\end{abstract}

Keywords: Peasant movement - Chilean left - Agricultural UnionAgrarian Reform - Smalls Farmers.

\footnotetext{
* Articulo perteneciente al Proyecto Fondecyt № 1110285 titulado "Cuestión Campesina y Políticas Sociales Rurales durante el Frente Popular y los gobiernos radicales (1936-1952)”, junto a María Angélica Illanes.

${ }^{* *}$ Historiador, chileno, Magister en Historia, Universidad de Santiago de Chile, nicoacevedo@gmail.com
}

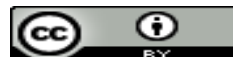




\section{Introducción}

El campesinado, a pesar de ser considerado por la izquierda marxista como un actor secundario, comparado con la clase obrera, cumplió un rol fundamental en una serie de movimientos y revoluciones en el siglo $\mathrm{XX}^{1}$. De esta manera, el pequeño y gran agricultor tuvo un rol mucho más prominente que el dado por la teoría marxista. En la actual emergencia de movimientos sociales la tendencia se ha mantenido: el protagonismo del campesinado ha superado el protagonismo del sindicalismo obrero. En el caso chileno, las lecturas mecánicas del marxismo afectaron la autonomía de estos movimientos agrarios, sobre todo a comienzos del siglo XX. El proyecto político de la izquierda supeditó a las primeras agrupaciones campesinas a la clase proletaria. Un momento clave fue el gobierno del Frente Popular (FP) en 1938' ${ }^{2}$ donde en dicha administración los campesinos no lograron obtener la reforma agraria ni la sindicalización campesina, como estipulaba su programa de gobierno ${ }^{3}$. La razón no fue el inmovilismo del trabajador agrario, sino al contrario, la represión patronal y estatal en contra de su movilización ${ }^{4}$, pero también en algún sentido el sometimiento de la izquierda chilena del proyecto agrario a la noción de revolución proletaria.

El presente artículo analiza la estrecha relación de los partidos políticos de izquierda con el movimiento campesino, y cómo esto afectó en su autonomía como movimiento social. Hemos escogido profundizar en torno a la Liga Nacional de Defensa de los Campesinos Pobres (en adelante Liga de Camp. Pobres). Esta fue la primera organización campesina a nivel nacional, formada por militantes de la Izquierda Comunista (IC). Nuestra hipótesis sugiere que tanto su creación, como su desarticulación, estuvo relacionada con la escasa autonomía que logró generar frente a los partidos políticos de izquierda y al marcado accionar institucional que éstas agrupaciones políticas le impregnaron. Esto debe considerar otras variantes, como fue el escaso apoyo estatal a la sindicalización campesina y la represión patronal que sufrieron intensamente de 1939.

Entenderemos por autonomía como la capacidad desarrollada por una organización, que de forma simultánea combina la supervivencia social, la acción política y la construcción

\footnotetext{
${ }^{1}$ A modo de ejemplo podemos mencionar la revolución de México (1910), Rusia (1917), China (1939), Cuba (1959), Vietnam y Nicaragua (1979). Eric Wolf, Las luchas campesinas del siglo XX (Ciudad de México: Editorial Siglo XXI, 1999).

${ }^{2}$ Michael Lowy, El Marxismo en América Latina (Santiago: LOM Ediciones, 2007), 11.

${ }^{3}$ Pedro Milos, Frente Popular en Chile. Su configuración: 1935-1938 (Santiago: LOM Ediciones, 2007), 340341.

${ }^{4}$ Brian Loveman, El mito de la marginalidad: participación y represión del campesinado (Santiago: ICIRA, 1971).
} 
de relaciones sociales no capitalistas ${ }^{5}$. Esto no excluye que los movimientos sociales bloqueen sus vínculos con la institucionalidad estatal, sino que más bien generen una "nueva relación" con el Estado, donde combinen estrategias a nivel nacional y territorial. En ese sentido, nuestra mirada, más que centrarse en teorías sistémicas, estudiará a los movimientos sociales desde los propios sujetos, ya sea desde sus relaciones externas como internas. Esto, porque al contrario del cientista político, Sidney Tarrow, pensamos que los movimientos sociales latinoamericanos no surgen sólo "cuando se dan las oportunidades políticas", sino que, en algunas ocasiones, son ellos mismos que generan cambios subterráneos, que se anticipan a los cambios estatales, obligando a la institución a considerarlos y a legislar sobre ciertas temáticas sociales ${ }^{7}$. En ese sentido, como plantea Gabriel Salazar, es necesario estudiar a los movimientos sociales desde su propia especificidad histórica y no trasplantar conceptos europeos en sociedades que ni siquiera han llegado a proceso de industrialización ${ }^{8}$. Álvaro García Linera, en ese mismo sentido, sostuvo que la izquierda marxista cometió el error de analizar el mundo agrario latinoamericano, considerando que "todos los pueblos del mundo tendrían que recorrer caminos similares a los de Europa”, es decir, los modos de producción que Marx describió en 1859: sociedad primitiva, feudalismo, democracia burguesa y socialismo ${ }^{9}$. Al contrario, para García Linera, Marx nunca concibió que la historia de nuestro continente pudiera ser homologada mecánicamente a la experiencia europea ${ }^{10}$. En Chile, la izquierda se apropió de estas lecturas, considerando que nuestro desarrollo rural era parecido al feudalismo ${ }^{11}$. De allí, que el movimiento obrero supeditó a la naciente movilización campesina a través de su alianza política. El triunfo del FP y su plan agrario, fue un claro ejemplo de esta estrategia. Lo planteó Como el Secretario General del Partido Comunista (PC), Carlos Contreras Labarca: "el programa agrario... pretende satisfacer no solamente las reivindicaciones de los más pobres, sino también de los sectores más vastos de la población rural. Busca rehabilitar la agricultura y aportar prosperidad y bienestar a las granjas”. Para ello Contreras Labarca abogaba a apoyar la candidatura del candidato radical Pedro Aguirre Cerda, político muy cercano a los grandes agricultores. Esto en contraposición

\footnotetext{
${ }^{5}$ Raúl Zibechi, Autonomía y emancipaciones. América Latina en movimiento (Santiago: Editorial Quimantú, 2008), 39-40.

${ }^{6}$ Sidney Tarrow, El poder en movimiento. Los movimientos sociales, acción colectiva y la política (Madrid: Alianza Editorial, 1998), 17.

${ }^{7}$ Alberto Merlucci, Acción colectiva, vida cotidiana y democracia (Ciudad de México: El Colegio de México, 1999), 11.

${ }^{8}$ Gabriel Salazar, Los movimientos sociales en Chile. Trayectoria histórica y proyección política (Santiago: Uqbar Editores, 2012), 404-405.

9Álvaro García Linera, La potencia plebeya. Acción colectiva e identidades indígenas, obreras y populares en Bolivia (Buenos Aires: FLACSO Co ediciones y Prometeo Libros, 2008), 26.

${ }^{10}$ García Linera, 26.

"Juan Chacón, El problema agrario y el Partido Comunista, informe presentado ante el XI Congreso Nacional del Partido Comunista de Chile, celebrado en Santiago de Chile los días 19 al 25 de diciembre de 1939 (Santiago: Ediciones del Comité Central del Partido Comunista de Chile, 1940), 5.
} 
a la fracción "trotskista" que estaba, según Contreras Labarca, por "minar el Frente Popular" ${ }^{12}$. Pero fueron precisamente estas agrupaciones, acusadas de trotskistas, las pioneras en la organización campesina, las cuales aportaron a la creación de la Liga de Campesinos Pobres, pero con las mismas lógicas y lecturas mecánicas del marxismo.

\section{El debate público sobre cuestión agraria}

Cuando se creó la Liga de Camp. Pobres en 1935, el debate público sobre la cuestión agraria ya estaba presente, sobre todo en torno a dos temáticas: la reforma agraria y la sindicalización campesina. Sobre lo primero, a comienzos de los años treinta se estimó que de las 23 millones de hectáreas agrícolas, más de la mitad estaban en poder de 599 propietarios ${ }^{13}$. Las discrepancias entre socialistas y social-cristianos estaban entre realizar una reforma agraria o seguir con la política de subdivisión de la Caja de Colonización Agrícola ${ }^{14}$. Esta institución fue creada en 1928 en la dictadura de Carlos Ibáñez del Campo ${ }^{15}$, pero tuvo reparos por diversos sectores conservadores, como el de Francisco Encina, quien estimó que su gestión tuvo un "criterio simplista", ya que la repartición de tierras no aseguraba el mejoramiento de la productividad ${ }^{16}$. Por otro lado, sobre la organización campesina, el propio Pedro Aguirre Cerda (dirigente radical y agricultor), basado en las experiencias europeas, planteó que en Chile se "ha llevado a la agricultura a un estado de inferioridad manifiesto con respecto a la industria”. A su criterio el Estado debía ser el garante de la organización para que se diese una armonía social en torno a los intereses del país ${ }^{17}$. En el caso de la sindicalización, hay quienes estimaban que debía formarse sólo por pequeños propietarios y no de obreros agrícolas como en las ciudades. De ésta forma se evitaba el peligro de las huelgas en tiempos de $\operatorname{cosecha}^{18}$. Al contrario, otros insistieron que el Código del Trabajo de 1931 y los convenios internacionales suscritos en las Conferencias Internacionales del Trabajos de Ginebra, autorizaban la sindicalización rural, teniendo solo las dificultades de la relación patronal y la propia ignorancia y analfabetismo del campesinado ${ }^{19}$.

Efectivamente el Código del Trabajo no negó la sindicalización en el campo, pero tampoco la explicitó literalmente. Sólo quedaban excluidos los trabajadores que prestaban

\footnotetext{
${ }^{12}$ Lowy, 149-150.

${ }^{13}$ Leoncio Chaparro, Colonización y Reforma Agraria: Hacia una distribución más justa de la tierra en Chile (Santiago: Imprenta Nascimento, 1932), 17.

${ }^{14}$ Chaparro, 17; Eduardo Frei Montalva, Chile desconocido (Santiago: Editorial Ercilla, 1937), 155-160.

${ }^{15}$ Caja de Colonización Agrícola, La Ley N 4.464 y su reglamento (Santiago: Impr. Nacional, 1929).

${ }^{16}$ José Garrido (Ed.), Cristian Guerrero y María Soledad Valdés, Historia de la Reforma Agraria en Chile (Santiago: Editorial Universitaria, 1988), 75.

${ }^{17}$ Pedro Aguirre Cerda, El problema agrario (Santiago: Universidad de Chile, 1929), 397- 426.

${ }^{18}$ Alfredo Bowen, Ensayo sobre el movimiento sindical y el sindicalismo agrícola (Santiago: s/e, 1933 ), 108.

${ }^{19}$ Carlos Lizama, La sindicalización campesina (Santiago: Imprenta Sur, 1939), 94-95.
}

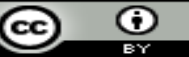


"servicios al Estado, a las Municipalidades o que pertenezcan a empresas fiscales" ${ }^{20}$. Con la administración de Arturo Alessandri (1932-1938), la Dirección del Trabajo autorizó la formación de 93 sindicatos agrícolas ${ }^{21}$, pero frente a la movilización en algunos fundos, el gobierno decidió suspender de facto la sindicalización campesina mediante un telegramacircular en 1933. Tal iniciativa dio el respaldo a la Sociedad Nacional de Agricultura (SNA), ya que ellos estimaron como un "error" aplicar las leyes sociales en el campo ${ }^{22}$. Con la formación del FP en 1936 y el triunfo que obtuvieron dos años después, surgió nuevamente el debate sobre la cuestión agrícola. Comenzó un nuevo ciclo de movilización campesina, que se graficó en la formación de más de 200 sindicatos y la presentación de más de 500 pliegos de peticiones entre 1939-1941 ${ }^{23}$. Nuevamente las asociaciones patronales escribieron al mandatario, quien decidió formar una comisión mixta que estudió una ley de sindicalización. En marzo de 1939 se suspendió la formación nuevos sindicatos agrarios, pero en vez de ser una decisión temporal, se eternizó producto de la falta de voluntad política de Aguirre Cerda y el Partido Radical de resolver el conflicto ${ }^{24}$. Los partidos de izquierda, si bien fueron críticos con tal medida, no rompieron con el FP, sobre todo para evitar el avance del fascismo. En conclusión, el programa de distribución de tierras desarrollado por la Caja de colonización Agrícola fue insuficiente, sobre todo porque no se modificó la alta concentración de propiedades en pocas manos y la sindicalización fue duramente reprimida, al igual que las huelgas campesinas. El poder patronal se intensificó utilizando el desalojo para "expandir su control al interior de la hacienda” como también para la "disminución de siembras como presión política a los gobiernos" radicales y Frente Populares (1938-1952) ${ }^{25}$.

\section{La formación del Frente Popular}

El Frente Popular fue una coalición formada en 1936 por los partidos Comunista, Socialista, Izquierda Comunista, Radical, Democrático y Radical Socialista. En general, los estudios en torno a su configuración, se han centrado en aspectos políticos, económicos y

\footnotetext{
${ }^{20}$ Código del Trabajo con todas sus modificaciones y reglamentos (Santiago: Edición del 'Diario Oficial' Imprenta La Nación, 1934), 92.

${ }^{21}$ Brian Loveman, Antecedentes para el estudio del movimiento campesino chileno: pliegos de peticiones, huelgas y sindicatos agrícolas, 1932-1966 Vol. I- II (Santiago: ICIRA, 1971).

${ }^{22}$ Brian Loveman, Struggle in the Countryside: Politics and Rural Labor in Chile, 1919-1973 (Bloomington: University of Indiana Press, 1976), 117- 118.

${ }^{23}$ Loveman, Antecedentes.

${ }^{24}$ Almino Affonso, Movimiento campesino chileno, 2 vols. (Santiago: ICIRA, 1970).

${ }^{25}$ María Angélica Illanes, "En los caminos de la patria. El desalojo campesino como castigo político patronal. Chile, 1938-1947” (2014), Inédito.
} 
sociales, dejando marginado su vínculo con la cuestión agraria ${ }^{26}$. $\mathrm{Al}$ contrario de lo que se ha planteado tradicionalmente, a mediados de los años treinta, los partidos políticos de izquierda intensificaron su relación política con el campo chileno, ya que estos fueron consideramos como aliado al proyecto del proletariado. ¿Cómo se planteó ésta alianza? Para el PC desde 1935, al ser concebido la revolución por "etapas", la clave fue "transitar a una etapa 'democrático- burguesa', principalmente antiimperialista, antes de avanzar hacia el socialismo. El objetivo socialista se postergaba" ${ }^{27}$. De esta manera, los campesinos fueron integrados a la política del PC, pero contradictoriamente, en base de una concepción de postergación. Desde la disidencia, Humberto Mendoza de la IC, criticó ésta táctica, ya que estimó que la verdadera contradicción no era entre democracia y fascismo, sino entre éste último y el socialismo, por ende ponía su intención en la creación de un Frente Único, en vez de uno Popular (rechazando la integración en un conglomerado con los radicales) ${ }^{28}$. Por otro lado, los socialistas estuvieron reticentes a esta coalición, pero finalmente aceptaron integrarse al FP en 1936. Su líder Marmaduke Grove fue candidato a la presidencia y gran defensor de la "revolución agraria". En una de las propagandas en torno a su campaña, el PS definió que su movimiento estaba "destinado a libertar al pueblo, obreros, campesinos y

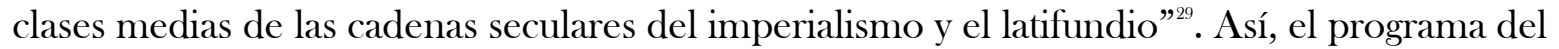
FP integró las demandas campesinas, realizando una extensa campaña en los campos chilenos en busca del apoyo del pequeño agricultor, inquilinos, medieros, peones y arrendatarios, es decir, del diverso mundo campesino. Las juventudes políticas se dedicaron en 1938 a recorrer los fundos, asistiendo incluso a las a las fiestas campesinas a realizar la campaña en favor de Aguirre Cerda. Una de las medidas fue en torno a la alfabetización. "El Frente Popular extirpará por todos los medios el analfabetismo, creará cientos de hermosas y modernas Escuelas para la infancia, establecimiento profesionales y técnicos para toda la juventud y despertará así tantas conciencias dormidas" ${ }^{30}$. Dichas demandas fueron acompañadas por una propaganda en favor del FP en forma de rima de manera de establecer un vínculo con la cultura campesina: "Campesino. Cuando vengas a votar. Buscar el Frente Popular/ Si votas por las Derechas. Siembras pero no cosechas/ El hombre de corazón. Nunca se vende al patrón. Tu rancho harás respetar. Con el Frente Popular. Trigo, papas y porotos. Cosecharás con tu voto/ Se perderá esta cosecha. Si votas por la Derecha ${ }^{\prime 31}$.

\footnotetext{
${ }^{26}$ Milos; Tomás Moulián, Fracturas. De Pedro Aguirre Cerda a Salvador Allende 1938-1973 (Santiago: LOM Ediciones, 2006) y Mario Garcés, Movimiento obrero en la década del treinta y el Frente Popular (Santiago: Tesis de Licenciatura, Universidad Católica, 1985).

${ }^{27}$ Milos, 77.

${ }^{28}$ Jorge Levín, "El Frente Único como especulación y como realidad”, Izquierda (Santiago), 29 de agosto de 1934, 3.

${ }^{20}$ Partido Socialista, Grove, el militar y el ciudadano (Santiago: Secretaria Nacional de Cultura y Propaganda, 1937), 23.

${ }^{30}$ "Cultura", Mundo Nuevo. Periódico de las Juventudes Comunistas (Santiago), 24 de septiembre de 1938, 5.

${ }^{31}$ Archivo Nacional, Ministerio de Interior, vol. 9788, Santiago, 1938.
} 
Finalmente el FP logró su cometido el 25 de octubre de 1938, llevando a la Presidencia de la República a Pedro Aguirre Cerda. El triunfo fue principalmente posible con votos de zonas mineras y urbanas, pero en localidades rurales como Temuco, Lonquimay, Villarrica, Curacautín, Cunco y Ovalle se logró superar al candidato de derecha, Gustavo Ross ${ }^{32}$. Con dicho triunfo comenzó un nuevo ciclo político en el campo, lográndose generar nuevos sindicatos, tarea difícil, pero que tuvo el apoyo de la izquierda chilena. Pero, ¿Cómo era incorporado e campesinado al proyecto del proletariado?

\section{Marxismo y campesinado}

El accionar realizado en los campos chilenos se basó en la mecánica lectura que la izquierda tuvo del marxismo a comienzos del siglo XX. Pero no sólo eso. La revolución proletaria insurreccional fue postergada además por la fuerte la represión que la dictadura de Ibáñez ejerció en contra de la izquierda marxista. Luego de un convulsionado ciclo de luchas obreras, el movimiento obrero fue institucionalizado mediante el Código del Trabajo de 1931. La izquierda se debatió en torno al sindicalismo legal, teniendo fuertes pugnas entre comunistas y anarquistas, ya que estos últimos no estaban por legalizar la lucha sindical ${ }^{33}$. Finalmente la izquierda adoptó, con un lenguaje ambiguo, el camino legal en torno a la transformación social. Esto se reflejó en torno a la formación de sindicatos agrícolas en las zonas rurales. Según nuestros conocimientos, las primeras movilizaciones fueron entre 19191921 fomentadas por la Federación Obrera de Chile bajo el liderazgo de Luis Emilio Recabarren $^{34}$. Un segundo intento fue impulsado por la IC desde 1933, cuando el diputado Emilio Zapata visitó algunos fundos de alrededores de Santiago. Esto, más el levantamiento de Ranquil y su posterior represión demuestran, por un lado, la actitud represora del gobierno de Alessandri a la lucha campesina, y por otro que la izquierda comenzó a influir, aunque lentamente, en los campos chilenos ${ }^{35}$.

Esta decisión de inserción política al campo estuvo mediada por la lectura esquemática del marxismo. Para esto tomaremos uno de los libros más influyentes del marxismo en los años treinta: "Fundamentos del Leninismo", de Joseph Stalin. Quien fuera considerado "el jefe de los pueblos", dio una breve receta del método leninista en torno a la dictadura del proletaria, la cuestiona campesina y rol del partido. Sobre el problema agraria, Stalin aclaró que sería falso que para Lenin "lo fundamental en el leninismo es la cuestión

\footnotetext{
${ }_{22}$ "Informe del Ministerio del Interior", Frente Popular (Santiago), 26 de octubre, 1938, 4.

${ }^{33}$ Mario Garcés, El despertar de la sociedad. los movimientos sociales en América Latina y Chile (Santiago: LOM Ediciones, 2013), 97-98.

${ }^{34}$ Sergio Grez, Historia del comunismo en Chile. La era de Recabarren 1912-1924 (Santiago: LOM Ediciones, 2011), $238-247$.

${ }^{35}$ Olga Ulianova, "Levantamiento Campesino de Lonquimay y la Internacional Comunista", Revista Estudios Públicos (Santiago), № 89, 2003.
} 
del campesinado", sino que el punto de partida del líder de la revolución rusa sería "la dictadura del proletariado". De esta manera, "la cuestión campesina, como cuestión del aliado del proletariado en su lucha por el Poder, es una cuestión derivada” ${ }^{\text {"6 }}$. El PC chileno entendió que el campesino era fundamental para la lucha revolucionaria, pero dentro de una alianza más amplia, ya que desde 1935, el Congreso de la Internacional Comunista recomendó la creación de Frentes Populares, producto del avance del fascismo en Europa ${ }^{37}$. Ese mismo año el Comité Central del Partido Comunista lanzó un manifiesto por la constitución del FP, planteando tres años después que fue la clase obrera la fuerza social fundamental para su triunfo electoral. Pero se debía ir al campo, porque "la reacción es todavía más poderosa que el Frente Popular en el campo" ". Además, el PC quiso combatir al "trotskismo" en torno a su trabajo campesino, superando el sectarismo e incorporando a los agricultores progresistas a la lucha (radicales por ejemplo) ${ }^{39}$.

La alusión de Carlos Contreras Labarca en torno al trotskismo y el campo, se debió precisamente porque la primera organización campesina a nivel nacional la organizó la disidencia del PC, la Izquierda Comunista. Esta, considerada anti-estalinista, fue formada en 1933 bajo el liderazgo de Manuel Hidalgo y Humberto Mendoza. Uno de sus dirigentes, el diputado Zapata, fundó dos años después la Liga de Camp. Pobres, considerando que "ningún hecho revolucionario que inicie el proletariado, podrá alcanzar el éxito, si acaso no se acompaña con la acción del campesinado" ". Pero, al igual que el PC, la IC estaba por la organización del campesinado, pero bajo el liderazgo del proletariado. Incluso el propio León Trotsky habría afirmado en 1906 que "el proletariado en el poder aparecerá ante el campesino como su liberador" ". En cambio, el Partido Radical Socialista criticó precisamente a la presencia de la IC en el campo chileno, porque la "posición histórica de Trotsky de negar el carácter revolucionario del campesinado", ha sido contrabandeada "hoy en Chile por los elementos hidalguistas, que alimentan y se alimentan de esta incomprensión" ${ }^{* 2}$. A continuación analizaremos la formación y desarrollo de la Liga de Camp. Pobres, poniendo atención a como la lectura del marxismo provocó una fuerte dependencia del movimiento al partido.

\footnotetext{
${ }^{36}$ José Stalin, Fundamentos del Leninismo (Santiago: Editorial Antares, 1938), 41.

J. Dimitrov, "El fascismo y la guerra”, Obras Completas, Editorial del PCB, 1954. http://www.marxists.org/espanol/dimitrov/1937jul.htm. Recuperado: 1 de julio de 2014 .

${ }^{38}$ Carlos Conteras Labarca, Unidad para defender la Victoria (Santiago: Editorial Antares, 1938), 38.

${ }^{39}$ Contreras Labarca, Unidad, 39.

${ }^{40}$ Loveman, Struggle, 152.

${ }^{41}$ Isaac Deutscher, Trotsky, el profeta armado (Santiago: Ediciones LOM- ERA, 2007), 145.

${ }^{42}$ "Los Radicales, Socialistas y los problemas de la unidad y de la tierra”, Frente Único (Santiago), $2^{\circ}$ semana de octubre de 1935,3 .
} 


\section{La organización del pequeño agricultor}

La Liga de Camp. Pobres se creó en 1935, principalmente por miembros de la IC. Pero sus antecedentes datan algunos años antes, cuando este partido planteó organizar a los trabajadores del campo a través de sindicatos, encontrándose con la negativa del gobierno de Arturo. De ésta forma la IC cambió su táctica, estableciendo otro tipo de organización: las Ligas o Comités Obreros, formados en cada fundo por asamblea general y así desarrollar los pliegos de peticiones $^{43}$. Las Ligas fueron una forma de organización popular en el ámbito habitacional (Ligas de arrendatarios) o de apoyo a estudiantes (Liga Protectora de Estudiantes Pobres), que fue replicado en los años treinta en el sector agrícola. En este caso, fueron las heladas de 1934 las que dieron la oportunidad de agrupación de los pequeños agricultores.

A mediados de los años treinta, la ciudad de Santiago estaba rodeado de cientos de parceleros y chacareros que abastecían con sus productos a gran parte de la población de la capital. A pesar de ser propietarios, estos estaban sumamente marginados de las políticas públicas. Hasta allí llegaron militantes de la IC, primero con la intención de organizar sindicatos, pero fue producto de una fuerte helada lo que terminó organizándolos. La catástrofe provocó que los pequeños agricultores sufrieran grandes pérdidas entre octubre y noviembre de 1934. Al año siguiente, el gobierno de Alessandri promulgó la Ley 5.558 que asignó 20 millones de pesos en préstamo a todos los agricultores damnificados. Pero según el diputado Zapata, sólo tuvieron acceso los grandes terratenientes, destinando sólo 5 millones de pesos a los pequeños campesinos. Según su análisis, los interesados sólo tenían treinta días para presentar una solicitud con la información de las extensiones y perjuicios afectados $^{4}$. Pero, producto a su aislamiento territorial, el campesinado pobre no tenía acceso a informarse sobre esta ley:

Yo he recibido serias protestas de este sector del campesinado, especialmente de las comunas de Renca, Quilicura, Tiltil, Polpaico, Batuco, Colina, etc, porque estas gentes no han podido acogerse a los beneficios de esta ley ${ }^{45}$

Se pidió extender el plazo, ya que existía más de un 50\% de los fondos aún por destinarse. Zapata asumió la representación de los pequeños agricultores, producto que el Ministerio del Trabajo les tenía "suprimido" el derecho de sindicalización. De esta manera, a

\footnotetext{
43 "Hacía la organización del campo", Izquierda (Santiago), 25 de Julio de 1934, 3.

" "Los Campesinos Pobres se dirigen a los trabajadores del país", Boletín de La Liga Nacional de Defensa de los Campesinos Pobres (Santiago), N 1, segunda quincena de enero de 1936, 1.

${ }_{45}$ "Facilidades para los pequeños campesinos trata de obtener el camarada Zapata", Izquierda (Santiago), 21 de Agosto de 1935, 2.
} 
petición de Zapata, la Cámara de Diputados pidió modificar el artículo $2^{\circ}$ para dar mayor plazo $^{46}$.

Paralelo a esto, los afectados por las heladas se reunieron en las diversas comunas, apoyados por la IC. Una de las primeras reuniones fue en Quinta Normal, en septiembre de 1935. Allí se tomaron los siguientes acuerdos: organizar una liga comunal, la cual debía tener representantes para fiscalizar el apoyo económico de la Ley 5.558. De esta manera se dan los primeros pasos, propagándose la formación de Ligas en Renca, Quilicura, San Bernardo, Talagante, Conchalí, Lampa, Maipú, Peñaflor y Barrancas ${ }^{47}$. Como primera característica, la Liga se constituyó en comités territoriales, que a la vez formaron Comités Provinciales y estos se relacionaron mediante un Ejecutivo Nacional. El liderazgo quedó conformado por Emilio Zapata, Bernardo Yuras y Carlos Acuña, todos militantes de la Izquierda Comunista. Cada Liga se compuso de un directorio de cinco personas por seis meses mínimos, pudiendo reelegirse $^{48}$. Tanto las ligas provinciales como el Ejecutivo debían financiarse por las cuotas de socios, lo que finalmente no logró sustentarse. Para Loveman, esto fue una de las principales causas de su desaparición en 1942, ya que existió una dependencia excesiva de las Ligas comunales con su dirigencia. Y es que la propaganda, los estatutos, los timbres, las solicitudes, etc, recayeron principalmente en este Comité Ejecutivo, y no del desarrollo propio de los pequeños agricultores. Estos comités no tenían personal a sueldo ni financiamiento. "No teníamos los recursos necesarios. Tal vez con más paciencia lo podría haber hecho mejor", cuenta Zapata en $1971^{49}$. Las gestiones jurídicas eran impulsadas generalmente por el propio Zapata, con procuradores y abogados voluntarios. Uno de ellos fue Oscar Waiss, también militante de la IC. Pero en 1937, tanto Waiss, como Zapata, Acuña y Yuras se integraron al PS producto de un acuerdo entre las directivas socialistas y la IC. De esta manera, las filas socialistas tomaron el control de la Liga de Camp. Pobres y los antiguos militantes de izquierda Comunista llamaron a los pequeños agricultores a votar en las próximas elecciones parlamentarias por el PS. Así lo indicó el primer número del Boletín de la Liga:

Trabajadores de la ciudad y del campo. Cerca de ti hay un arma que debes utilizarla y esgrimirla a favor de tu clase, el voto. Para ello es necesario que aproveches los 8 primeros días del mes, de 1 a 2 PM para la inscripción en los registros electorales. La oficina del Registro Civil tiene la obligación de atenderte ${ }^{50}$.

\footnotetext{
${ }^{46}$ "Zapata se refiere a las irregularidades en la distribución de los auxilios a los agricultores damnificados por las heladas", Izquierda (Santiago), 18 de septiembre de 1935, 1.

${ }^{47}$ Loveman, Struggle, 154- 155. Además en "La Ley de Colonización solo sirve para los latifundistas!", Consigna (Santiago), 12 de octubre de 1935, 2.

"48 "Por la liberación del campesinado", Consigna, 16 de noviembre, 1935, p. 2.

${ }^{49}$ Loveman, Struggle, 157.

${ }^{50}$ "La voz del Campesinado ante la Cámara de diputados", Boletín de La Liga Nacional de Defensa de los Campesinos Pobres (Santiago), N 1, segunda quincena de enero de 1936, 2.
} 
Con una autonomía relativa, la Liga pudo desarrollar mientras estuviera ligada a Zapata y los militantes del PS, pero las fuertes rencillas que hubo entre el socialismo, e incluso entre el PC, debilitó la organización campesina hasta el término de la Liga 1942. Pero antes de este desenlace, estudiaremos las reivindicaciones y los repertorios de acción de la Liga de Camp. Pobres.

\section{Reivindicaciones y movilizaciones campesinas}

En la medida que fueron pasando los meses desde su fundación, las reivindicaciones de la Liga de Camp. Pobres fueron ampliándose. Si bien en un comienzo estuvieron ligadas a la Ley 5.558, al mes siguiente se plantearon nuevas peticiones: la rebaja de los arrendamientos de tierras; la representación de los campesinos en las Cajas de Crédito Agrario, Junta de Exportación Agrícola y Caja de Seguro Obrero; el apoyo crediticio y de arriendo de maquinarias a pequeños agricultores; impedir el desalojo de parceleros que estén en la Liga, además de electricidad y mejoramiento de las viviendas en los predios ${ }^{51}$. Apoyados por la IC y el PS, las actividades y petitorios de la Liga se difundieron en el semanario socialista Consigna y el diario Izquierda $a^{52}$. La mayoría de las gestiones eran respaldadas por gel diputado Zapata desde el parlamento ${ }^{53}$. Esto creó una dinámica en donde la Liga se transformó entre 1936 a 1940 en una organización Nacional (desde Coquimbo a Puerto Montt), pero que buscó representar tanto a pequeños agricultores, como a inquilinos, arrendatarios y parceleros. En su primer Boletín se puede leer un mensaje general hacia el campesinado chileno:

Ha sonado tu hora hermano campesino. No debes continuar un solo momento bajo la bestial explotación de tu patrón (...) No temas a la criminal actitud de los terratenientes. Ve a formar parte de las Ligas de Defensa de Campesinos Pobres, sin tardanza y constitúyela ahí en el pueblo donde no exista... acuérdate a que ahora no estás solo, detrás de ti marcha toda la fuerza organizada del trabajador de la ciudad, quien te apoyará en cualquier situación ${ }^{54}$.

\footnotetext{
${ }^{51}$ Izquierda (Santiago), 15 de octubre de 1935, 1-4.

${ }^{52}$ "La Liga de Defensa de los campesinos pobres constituye hoy la primera fuerza organizada de campesinos", Izquierda (Santiago), 23 de octubre de 1935, 1.

${ }_{53}$ "Por las comunas rurales”, Izquierda (Santiago), 1 de noviembre de 1935, 4. Además de “Actividades por las ligas comunales”, Boletín de La Liga Nacional de Defensa de los Campesinos Pobres (Santiago), N 1, segunda quincena de enero de 1936, 3-4; "Liga de Defensa de Campesinos Pobres. Efectuar mañana una gran marcha”, La Hora (Santiago), 9 de mayo de 1936, 10.

${ }^{54}$ "Hermano campesino", Boletín de La Liga Nacional de Defensa de los Campesinos Pobres (Santiago), N ${ }^{\circ}$, segunda quincena de enero de 1936, 1.
} 
Dicho llamado, como hemos analizado anteriormente, se realizó desde un lenguaje externo: desde la ciudad, debido que el Ejecutivo Nacional era precisamente conformado obreros urbanos más que campesinos. Por otro lado las movilizaciones que adoptó la Liga fueron principalmente las concentraciones y peticiones a cargo de sus representantes. Las acciones directas o ilegales como tomas o saqueos estuvieron ausentes en sus repertorios. Por ejemplo, el 19 de enero de 1936 se realizó una concentración en Avenida La Paz para protestar por las cargas tributarias sobre los pequeños chacareros por parte de la Municipalidad de Santiago y los administradores del Mercado ${ }^{55}$. La Liga además estimó que era "una verdadera injusticia cobrar dos pesos de entrada por una carretela que apenas lleva a veces 10 pesos de artículos de consumo" $"$.

Finalmente el proceso inicial de la Liga se consolidó con el Congreso de Campesinos Pobres organizado el 21 de mayo de 1936, con la asistencia de 400 delegados. El evento contó con la presencia de Oscar Schnake, Marmaduke Grove y el diputado comunista Andrés Escobar, cuya presencia demostró el "espíritu unitario" de la jornada. Carlos Acuña finalizó con un recorrido histórico de las actividades y objetivos de la Liga, además de plantear la importancia de unirse al FP con "fuerzas que no comparten en un programa revolucionario de la lucha de clases ${ }^{\text {"57 }}$. Con ello enumeró una serie de reivindicaciones del Congreso: "derecho a la sindicalización campesina, salario mínimo, habitaciones higiénicas, protección de las obreras que participan en las faenas agrícolas (...) pago de horas extraordinarias con el recargo de 50\%, derecho al feriado anual de 15 días"; además de tener representantes en una serie de organismo estatales de crédito y asistencia social. Finalmente entre las medidas de mejoramiento social y cultural, se demandó la "instalación de los servicios de locomoción, gratuita para los niños escolares, extensión de luz eléctrica, agua potable, pavimentación de veredas, arreglos de calzada, puentes y desagües”, además de bibliotecas populares bajo el control de las organizaciones campesinas, escuelas nocturnas en los pueblos campesinos, represión al alcoholismo y juegos de azar ${ }^{58}$. El Congreso fue parte de la estrategia de integrar al campesinado y sus demandas al programa del FP, que generaron una tremenda expectativa, pero que más adelante no fueron capaces de cumplir.

\footnotetext{
${ }^{55}$ "Los Chacareros frente a las gabelas que impone a la Municipalidad de Santiago a los que envían a la Vega", Boletín de La Liga Nacional de Defensa de los Campesinos Pobres (Santiago), N ${ }^{\circ} 1$, segunda quincena de enero de 1936, 4. Además en "Una concentración de pequeños agricultores se efectuará el domingo", El Mercurio (Santiago), 17 de enero de 1936, 26.

${ }^{56}$ Oficio de Carlos Acuña dirigida a Alcalde de la Municipalidad de Santiago, en Boletín de Sesiones de Cámara de Diputados, $14^{\circ}$ sesión extraordinaria, 30 de marzo de 1936, 396.

${ }^{57}$ "La organización campesina", Consigna (Santiago), 30 de Mayo de 1936, 1.

${ }^{58}$ "Despertar de las masas campesinas", Izquierda (Santiago), 30 de mayo de 1936, 4.
}

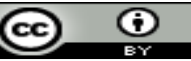




\section{La movilización campesina y el Congreso de Trabajadores Agrícolas}

Con el triunfo del FP, el Ejecutivo Nacional de la Liga de Camp. Pobres planteó que un solo hombre no era capaz de lograr cambios en la política agraria sino iba acompañado de "una organización poderosa". El problema agrario fue percibido como un asunto integral: "No es parcelando ridículamente algunos predios", sino acabando con el latifundio". Las gestiones siguieron dependiendo del diputado Zapata, quien logró la promulgación de la Ley 6290, la cual entregó 30 millones de pesos en préstamos a pequeños agricultores mediante la Caja de Crédito Agrario ${ }^{60}$. En torno a Pedro Aguirre Cerda, la Liga apostó que sería un buen gobierno, pero:

... Como estadista el Presidente tendrá que cumplir las promesas hechas como candidato: la solución del problema agrario... el campesino tiene puestos sus ojos en el nuevo mandatario... el latifundista constituye factor de intranquilidad social porque siendo grupo reducido impone sus intereses sobre los del país, acaparando el gobierno por medios de elecciones viciadas en que el trabajador agrícola no tiene libertad para manifestar su sentir ${ }^{61}$.

A comienzos de 1939, la Liga creció considerablemente, teniendo Ligas no sólo en los alrededores de Santiago, sino en Illapel, Salamanca, Santa Fe, Chilcoco, Alto Jahuel, Santa Inés, Casma, Osorno, Paine, San Felipe, Nos, Licantén, Santa Rosa de Lontúe e Isla de Maipo. En cada sector se eligieron directivas y se enviaron sus reclamos vía correo. Las denuncias generalmente fueron en torno a los malos tratos recibidos por los patrones y las condiciones deplorables de alimentación y vivienda ${ }^{62}$. Para ello la Liga decidió organizar el primer Congreso Nacional de Campesinos en mayo de 1939, de manera de convertirse en una Federación que representara no sólo a los pequeños agricultores, sino al movimiento de trabajadores agrícolas. El levantamiento de la suspensión de sindicatos permitió una segunda ola de movilización campesina, que según datos de Brian Loveman en 1939 se formaron el doble de sindicatos (202), en comparación al periodo entre 1932-1938 (93 sindicatos) $^{63}$. Esta feroz movilización asustó a la clase patronal, que nuevamente presionó al gobierno mediante cientos de desalojos. Finalmente Pedro Aguirre Cerda, convocó en marzo de 1939 a una

\footnotetext{
59 "Un partido que merece nuestra confianza", Boletín de La Liga Nacional de Defensa de los Campesinos Pobres (Santiago), № 2, diciembre de 1938, 3.

${ }^{60}$ "Préstamos para pequeños agricultores, medieros, inquilinos y parceleros", Boletín de La Liga Nacional de Defensa de los Campesinos Pobres (Santiago), N², diciembre de 1938, 1.

${ }^{61}$ Bernardo Yuras, "Vamos arando. Don Pedro Aguirre Cerda", Boletín de La Liga Nacional de Defensa de los Campesinos Pobres (Santiago), N² 2, diciembre de 1938, 3.

${ }^{62}$ “Actividades de la Liga”, Boletín de La Liga Nacional de Defensa de los Campesinos Pobres (Santiago), N ${ }^{\circ}$, enero de 1939, 3-4.

${ }^{63}$ Loveman, Antecedentes.
}

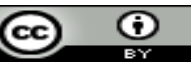


Comisión Mixta para tratar un proyecto de ley sobre Sindicalización Campesina. Respaldada por el PC, el PS y la CTCH, quienes enviaron a sus representantes, la Comisión debió funcionar por tres meses para trabajar un proyecto de Ley que consensuara los intereses patronales y sindicales. Aguirre Cerda accedió a la petición de la SNA suspendiendo la sindicalización campesina por mientras duró la discusión de la Comisión Mixta. El Proyecto de Ley ingresó en noviembre de 1939 al Parlamento, siendo estancado por la derecha y el Partido Radical, los cuales tenían intereses económicos en el campo. Zapata, quien ingresó a la Comisión Mixta como representante del PS y la Liga de Camp. Pobres, planteó que el gobierno debía detener los crueles desalojos que ejercían los terratenientes, además aceptar que el Código del Trabajo se aplicara en el campo. "El gobierno debe, de una vez por todas, hacer una declaración terminante: o continúa en Chile el feudalismo agrario o tienen los trabajadores rurales todo el derecho a organizarse y a las defensas y el apoyo que las leyes le permiten ${ }^{\prime 64}$.

En medio de aquella discusión se organizó el Congreso de Trabajadores Agrícolas, entre el 28 de abril y el primero de mayo de 1939. Dicho evento tuvo 39 delegados de Sindicatos de Pequeños Agricultores, Profesional y 56 representantes de las Ligas de Camp. Pobres desde Coquimbo hasta Aysén, logrado convertirse finalmente en la Federación Nacional Campesina, de tendencia claramente socialista. Los principales temas fueron la sindicalización campesina, mejorar la Ley de Colonización Agrícola, mejorar el alimento y las habitaciones de los inquilinos y que el Estado organice la producción y distribución agrícola ${ }^{65}$. La Federación planteó ampliar su trabajo hacia inquilinos y medieros, aunque los dirigentes fueron nuevamente los mismos dirigentes de la Liga: Zapata, Acuña y Bernardo Yuras, además de Julio Sotomayor, Alberto Galaz, Humberto Alfaro, Ramón Saavedra y José Muñoz (muchos de ellos socialistas). Dicho sea de paso la Federación no tuvo reconocimiento legal, pero se mantuvo por algunos años. Su creación le quitó protagonismo a la Liga, producto que la lucha de los sindicatos agrícolas tomó más fuerzas que la de los pequeños chacareros. Paradójicamente el Congreso campesino fue posible por dineros entregados por Aguirre Cerda a Zapata, ya que el PS no entregó "ni un centavo", como confesó Zapata en $1971^{66}$. Por otro lado, las diferencias entre los dos partidos más importantes de la izquierda (PS y PC), debilitó al movimiento de campesinos en general. Ambos partidos disputaron ser la "vanguardia" de la clase trabajadora y por ende, del campesinado.

\footnotetext{
${ }^{64}$ "Zapata. Líder del campesinado habla", Revista Rumbo (Santiago), № 1, segunda época, junio de 1939, 33.

${ }^{65}$ "Congreso Nacional de Campesinos inaugural hoy sus actividades”, La Nación (Santiago), 28 de abril de 1939, 10; "Temario del Congreso", Boletín de La Liga Nacional de Defensa de los Campesinos Pobres (Santiago), $\mathbf{N}^{\circ}$ 4, mayo de 1939, 1.

${ }^{66}$ Loveman, Struggle, 158.
}

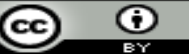




\section{Los conflictos entre comunistas y socialistas}

La represión que vivió el campesinado chileno entre 1939-1941 fue denunciada por la Liga de Camp. Pobres y los partidos de izquierda, pero con serios conflictos políticos entre sí. El PC junto con el PS no supieron resolver sus diferencias políticas en pos de un bien común, sino que causaron profundas divisiones en el movimiento obrero y campesino. $\mathrm{Al}$ contrario de lo que dicen los principales estudios políticos del FP, la izquierda chilena no fue parte de un "pacto por la industrialización", sino que tuvo reacciones diversas en torno al Proyecto de Sindicalización parlamentario de noviembre de 1939. Por un lado el PC, estuvo por paralizar la sindicalización, pero sólo mientras se discutía el proyecto. A fines de 1939, Juan Chacón, como encargado de la comisión Agraria, hizo una autocrítica por subestimar, como partido, al campesinado, debido que "la revolución chilena, la masa agraria deberá ocupar un papel de primer plano, y su participación pasará profundamente en la orientación de aquella, estrechamente vinculada al movimiento de los obreros de la ciudad, pues la población campesina es la mitad de la población del país" ${ }^{67}$. En torno a la sindicalización campesina, más que un proyecto, el PC abocó por la aplicación de Código del Trabajo ${ }^{68}$. Por otro lado, Chacón Corona acusó a los "trotskistas" de dividir las "capas inferiores del campesinado", para que luchen de manera aislada de los inquilinos y medieros. Una crítica dirigida precisamente con la Liga de Camp. Pobres, negando su Congreso de abril de 1939, llamando constituir una Federación Nacional de Sindicatos Agrícolas ${ }^{69}$. Según Loveman, esta reticencia se debió a que la Liga amenazó los deseos del PC "por la hegemonía del movimiento campesino y el control de la $\mathrm{CTCH}^{\prime \prime}{ }^{\prime 0}$. En caso de la Central de Trabajadores de Chile, finalmente a nivel nacional, aunque con reticencias de los comunistas, integraron a la Liga, pero en julio de 1939, frente al segundo Congreso Nacional de la CTCH, el PC negó la participación de "trotskistas" como delegados de los "llamados Campesinos pobres". A pesar de sus pugnas, Zapata y la Liga, lograron tener representación, enfrentándose a los comunistas y llevando a la victoria al socialista Bernardo Ibáñez como Secretario General del la central ${ }^{71}$.

Pero los conflictos dentro del PS no estuvieron ausentes. Siendo un partido heterodoxo y con un fuerte caudillaje de sus líderes Grove y Schnake, una fracción, autodenominada como "inconformistas", criticó la postura ambigua de la dirección socialista frente al conflicto agrario y por acomodarse en puestos administrativos. La dirección de Grove decidió expulsar a uno de los fundadores de dicho movimiento: Cesar Godoy Urrutia,

${ }^{67}$ Chacón Corona, 5.

${ }^{68}$ Chacón Corona, 42.

${ }^{69}$ Chacón Corona, 33.

${ }^{70}$ Loveman, Struggle, 160.

${ }^{71}$ Loveman, Struggle, 162.

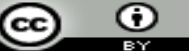


el cual formó el Partido Socialista de Trabajadores (PST) ${ }^{72}$. Zapata, con otros dirigentes ligados a la Liga, se unieron al PST afirmando:

Ellos, los oficialistas, han estafado al campesinado, prometiéndoles la tierra a los que la trabajan y firmando acuerdos con los latifundistas para impedirles su sindicalización: predicando el principio de que no habrá tierras sin hombres ni hombres sin tierras y negociando fundos en la Caja de Colonización en beneficio personal. Y fui su cómplice al haberme limitado a denunciar en nuestros organismos internos estas traiciones y estos escándalos y no haberlo hecho desde un comienzo públicamente a los trabajadores de mi país ${ }^{73}$.

La Liga, disminuida por el intenso trabajo en torno a la sindicalización campesina y el quiebre en el PS, terminó fragmentada, pero no desapareció. En 1940, por ejemplo, la Liga de Llay Llay denunció a la CTCH la persecución y despidos que eran víctimas de los terratenientes $^{74}$. La gestión de la bancada de parlamentarios de PST tampoco se detuvo. En nombre del campesinado, se manifestó en contra de la suspensión de sindicatos, insistiendo que el Código del Trabajo permitía dicha tramitación. En agosto de 1940 presentaron un contraproyecto el cual abogó por mejorar la legislación en torno a los sectores rurales. Su propuesta no llamó a armonizar las relaciones sociales en el campo, sino en torno a proteger los intereses de "la clase trabajadora del campo" ${ }^{75}$. Por otro lado, la brigada del PST, formada por Godoy Urrutia, Carlos Rosales, Jorge Dowling, Natalio Berman y Emilio Zapata continuó con su lucha de fiscalización y petición al gobierno, denunciando entre otros aspectos los atropellos de los trabajadores del campo en diversas comunas ${ }^{76}$. Pero sus gestiones fueron infructuosas, tanto por arremetida latifundista, como por la decisión de “orden y conciliación de conflicto social” de parte del gobierno de Aguirre Cerda.

\section{La Disolución de la Liga de Campesinos Pobres}

En 1941 el PST sólo logró la reelección de Natalio Berman por la zona del Bío Bío, mientras que Zapata, Dowling, Rosales y Godoy Urrutia perdieron sus cupos parlamentarios.

\footnotetext{
${ }^{72}$ Jorge Arrate y Eduardo Rojas, Memoria de la izquierda chilena. Tomo 1. 1850-1970) (Santiago: Javier Vergara Editor, 2003), 223-224.

${ }^{73}$ "Dice Emilio Zapata: Acusamos a los lideres Grove y Schnake de llevar al Partido Socialista hasta el charco putrefacto de la socialdemocracia”, VEA (Santiago), N 58, 1940, 11.

${ }^{74}$ Oficio de Bernardo Ibáñez, Secretario General de la CTCH a Juan Pradenas, Ministro del Trabajo, Santiago, 18 de mayo de 1940. Archivo Nacional, Dirección General del Trabajo, Vol. 1146.

${ }^{75}$ Proyecto completo en Boletín de Sesiones de Cámara de Diputados, Sesión Ordinaria del 14 de agosto de 1940, 2126- 2131.

${ }^{76}$ Peticiones en Boletín de sesiones de Cámara de Diputados, Sesión Ordinaria del 16 de octubre de $1940,44$.
} 
Para Loveman ésta derrota no sólo tuvo consecuencias políticas para el PST, sino también para el futuro de la Liga de Camp. Pobres, perdiendo sus aliados claves en la Cámara de Diputados. Por otro lado, Bernardo Yuras, el único campesino en el Comité Ejecutivo de la Liga, renunció por conflictos con Carlos Acuña, quien también militó en el PST. Según Loveman la disolución de la Liga fue "tranquila a pesar de los esfuerzos débiles, incluidos de Marmaduke Grove, de mantener al menos algo parecido a la actividad de Liga. Con una débil estructura organizativa, la Liga no podría sostenerse sin Zapata" ${ }^{77}$. Efectivamente, el PS liderado por Marmaduke Grove intentó reorganizar la Liga, mediante encuentros en diversas regiones, afirmando que si bien "la sindicalización campesina puede satisfacer las necesidades inmediatas de los agricultores modestos; pero solo la reforma agraria interpreta la solución integral de su problema" ${ }^{\text {". }}$. La desunión de la izquierda en torno al programa político, se evidenció también en la lucha agraria. Por otro lado, como planteó Alan Angell en su estudio sobre los partidos y el movimiento obrero, la relación entre ambas instituciones fortaleció el movimiento campesino de la época, pero creó una estrecha dependencia ${ }^{79}$. Es decir, la movilización campesina se vio extremadamente afectada por las disoluciones y conflictos entre la izquierda. Siguiendo con la breve historia del PST, en 1942, el partido liderado por Godoy Urrutia, se vio aislado del gobierno y el parlamento. Esto les significó moderar sus críticas y buscar nuevas alianzas. En su Tercer Congreso, el PST asumió la lucha mundial contra del fascismo e ingresó a la Alianza Democrática, para apoyar a Juan Antonio Ríos, candidato Radical a la Presidencia de la República. En materia agraria se planteó reestructurar la Liga de Camp. Pobres, la cual estaba en manos del PS oficial. Ante el reclamo de las Ligas por obtener el reconocimiento legal, se propuso pedir la personalidad jurídica, siguiendo con el histórico legalismo de parte de las masas campesinas organizadas, las cual aún creían en la estructura legal de sus acciones ${ }^{80}$. Pero estos deseos no fueron concretados. La aparición de la Liga, hasta donde hemos conformado, fue hasta septiembre de 1942 con la formación de la Federación Industrial Nacional de Trabajadores Agrícolas (FINTA). Este evento, que logró reunir a decenas de sindicatos agrícolas y agrupaciones agrarias, tenía una reconocida influencia del PC y del PST, ya que quienes realizaron el informe final fue Juan Chacón Corona y Justo Zamora, diputados comunistas en ese momento. En el informe final, Chacón Corono lanzó la tesis de "Unidad Nacional contra el nazifascimo”, donde propuso que el campesinado debía integrarse a dicho camino, abogando a la expropiación de tierras, solamente pertenecientes al "nazi fascismo y

\footnotetext{
${ }^{77}$ Loveman, Struggle, 164.

${ }^{78}$ "Dijo Grove: hay que entregar la tierra a los que la trabajan y son capaces de hacerla producir y prosperar", Consigna (Santiago), 2 de noviembre de 1940, 1 y 5.

${ }^{79}$ Alan Angell, Partidos políticos y movimiento obrero en Chile. De los orígenes hasta el triunfo de la Unidad Popular (Ciudad de México: Ediciones ERA, 1974).

${ }^{80}$ Partido Socialista de los Trabajadores, El Camino del Pueblo. Resoluciones del Tercer Congreso General del Partido Socialista de Trabajadores (Santiago: Ediciones Combate, 1942), 51- 54.
} 
saboteadores de la producción" ${ }^{\sharp 1}$. En torno a la sindicalización, la FINTA se negó a una legislación "especial”, ya que las disposiciones vigentes del Código del Trabajo lo permitían. Es por ello que pidió al gobierno de Juan Antonio Ríos que permitiera la libre asociación. Por otro lado, se realizaron propuestas para medieros, colonos, pequeños agricultores y la raza indígena. Los únicos delegados por la Liga de Camp. Pobres fueron Manuel Cabrera y Emilio Zapata, quienes representaban a las comunas de Olmué y Limache. Zapata además fue encargado del evento Asesor del Consejo Directivo Nacional junto con Cesar Godoy Urrutia y Natalio Berman ${ }^{82}$. Al año siguiente, tanto Berman como Godoy Urrutia, propusieron la fusión del PST con el PC, influidos por la disolución de la Tercera Internacional, la cual propuso "el reagrupamiento de todas las fuerzas populares y progresistas en un solo y gran partido" ${ }^{\text {. }}$. A través de un Comité de Enlace la propuesta también llegó al PS, el cual después de una serie de conversaciones, se negaron rotundamente. En el PST, Zapata y otros militantes, se negaron a la formación de "un partido único", siendo expulsados a comienzos de 1943 acusados de fraccionalistas ${ }^{84}$.

Con el desaparecimiento de la Liga de Camp. Pobres y la lucha de los pequeños agricultores, se cerró un ciclo en la cuestión agraria en Chile. Creemos que esto se vio influido tentativamente por tres razones. Primero, con el gobierno de Pedro Aguirre Cerda, los pequeños agricultores se vieron beneficiados por una Ley 6382, la cual propuso ayudar económica a parte de los 331.357 pequeños agricultores del país, proporcionándoles "semillas, abonos, útiles, enseres, máquinas, animales, dinero, etc" ${ }^{\text {" }}$. Un estudio más profundo dicha legislación nos podría revelar qué relación, pudo tener esta ley, con la baja de protagonismo de aquel sujeto social desde el gobierno del FP. Por otro lado, podemos determinar que desde 1939 la opinión pública fue testigo de la irrupción de la movilización de los sindicatos agrícolas. Estos levantaron cientos de pliegos de peticiones y fueron victoriosos de algunas huelgas y movilizaciones. El terror que provocaron generó que los gobiernos de Aguirre Cerda y Antonio Ríos no permitieran nuevos sindicatos agrícolas y finalmente la clase patronal logró despedir y desmembrar gran parte de este movimiento. ¿Es posible que los partidos políticos de la izquierda hayan preferido priorizar en la movilización sindical, descuidando a las organizaciones de agricultores? Puede ser. Si comparamos los congresos campesinos de 1939 (organizados por la Liga) y el evento de fundación de la FINTA en 1942, evidenciamos una baja de organizaciones de pequeños agricultores importante. Finalmente, los propios conflictos internos en la izquierda, influyeron de sobre

\footnotetext{
${ }^{81}$ Primer Congreso de Obreros Agrícolas, inquilinos y medieros, celebrado en Santiago los días 4,5, y 6 de septiembre de 1942 (Santiago: Impresora El Mundo, 1942), 10.

${ }^{82}$ Primer Congreso de Obreros Agrícolas, inquilinos y medieros, celebrado en Santiago los días 4,5, y 6 de septiembre de 1942 (Santiago: Impresora El Mundo, 1942), 46.

${ }^{83}$ "Propiciamos reagrupamiento de la clase obrera en el Partido Único”, Combate (Santiago), $1943,2$.

${ }^{84}$ Oscar Waiss, Un drama Socialista (Santiago: Editorial Victoria, 1948), 41-44.

${ }^{85}$ Javier Baeza Bernales, Cooperativas de Pequeños Agricultores (Santiago: Memoria de prueba para optar al grade de Licenciado de la Facultad de Ciencias Jurídicas y Sociales de la Universidad de Chile, 1940), 49.
} 
manera en la dinámica orgánica de la Liga de Camp. Pobres, los cuales además dependían económicamente de las gestiones de Emilio Zapata, como parlamentario.

${ }_{\mathrm{C}}$ Fue en vano la labor de la Liga de Camp. Pobres y los pequeños agricultores como afirmaría el Padre Hurtado en su clásico texto sobre sindicalismo en Chile $?^{86}$ Creemos que al contrario, entre 1935-1941 la Liga desarrolló una escuela de dirigentes y experiencia, la cual tuvo una importante influencia en los años posteriores, tanto en la formación de la FINTA entre 1943-1947, como la Asociación Nacional de Agricultores de Chile (ANACH). Esta última, de influencia comunista, proponía en 1947 organizar a las mismas comunidades y agrupaciones que hizo en su tiempo la Liga. Creemos que la influencia del PC en torno a este movimiento y a la FINTA, fue reforzada por el traslado de dirigentes campesinos socialistas ligados a la Liga, que pasaron a las filas del comunismo desde 1942. Esto fue el caso de José Ignacio Becerra, Carlos Donoso, Manuel Verdugo Droguett, Luis Muñoz y Adán Sanhueza (Liga de Camp. Pobres del fundo de Santa Fe). El caso de José Becerra es el más ejemplar de todos. Dirigente de la Liga de Camp. Pobres de Rinconada, comuna de Maipú, fue delegado en el Congreso de la Liga en 1939. Su nombre se repitió como delegado en 1942 en el Congreso organizado por Chacón Corona. ¿Cómo sostener que pasaría a formar parte del PC? Simple. En 1943 fue el dirigente nacional de la ANACH, de clara tendencia comunista ${ }^{87}$. Tanto la ANACH como la FINTA, fueron disueltas en 1947 producto de la Ley de sindicalización promulgada por el gobierno de Gabriel González Videla aquel año. Sus líderes fueron perseguidos al año siguiente por la Ley Permanente de Defensa a la Democracia. Nuevamente la represión política y patronal afectó el desarrollo del movimiento campesino, el cual continuó teniendo una estrecha autonomía de los destinos de las organizaciones políticas. ¿Pudo ser distinto? Evidentemente, por las condiciones geográficas de nuestro país y el sistema de control hacia el inquilinaje, era poco probable que los campesinos se organizaran a nivel nacional sin apoyo de los partidos políticos. Fue sin duda el aporte de la izquierda chilena, la que ayudó a nuclear las movilizaciones campesinas, dándole una amplitud nacional, logrando desarrollar objetivos y una plataforma en común. Pero, por otro lado, el tipo de movilización y la forma de organizarse fue tremendamente institucional, no permitiendo otro tipo de repertorios que pudieran sobrevivir a la represión e ilegalización de la movilización a partir de 1948. Las organizaciones sociales corrieron la misma suerte que las agrupaciones políticas. En el caso de la Liga de Camp. Pobres, la escasa autonomía les pasó la cuenta.

Recibido: 8 enero 2015

Aceptado: 14 marzo 2015

\footnotetext{
${ }^{86}$ Alberto Hurtado, Sindicalismo. Historia, Teoría, Practica, Editorial del Pacífico, Santiago, 1950, p. 222.

${ }^{87}$ "Convocatoria del primer Congreso Nacional de Agricultores de Chile a realizarse en Santiago los días 28 al 30 de enero de 1944”, El Campo, N 9, Santiago, primera quincena de diciembre de 1943, p. 2
} 


\section{BIBLIOGRAFÍA}

\section{Fuentes Primarias}

- Ministerio Interior (1936-1941)

- Dirección General del Trabajo (1939-1941)

- Boletín de la Cámara de Diputados (1936-1941)

\section{Diarios y Revistas}

- Periódicos Frente Único, Izquierda, Frente Popular, Rumbo, Consigna, La Nación, La Hora y Boletín de Liga de Defensa Nacional de Campesinos Pobres (1936-1939), VEA, El Campo.

\section{Libros, artículos, memorias, y folletos de la época}

- Acevedo Arriaza, Nicolás, "La voz del campo. La Política Agraria del Partido Comunista de Chile durante el Frente Popular (1936- 1940)", Olga Ulianova, Rolando Álvarez y Manuel Loyola, El Siglo de los comunistas chilenos. Santiago: Instituto de Estudios Internacionales, USACH, 2012.

- Affonso, Almino, Movimiento campesino chileno, 2 Vols. Santiago: ICIRA, 1970.

- Aguirre Cerda, Pedro, El problema agrario. Santiago: Universidad de Chile, 1929.

- Angell, Alan, Partidos políticos y movimiento obrero en Chile. De los orígenes hasta el triunfo de la Unidad Popular. Ciudad de México: Ediciones ERA, 1974.

- Arrate, Jorge y Rojas, Eduardo, Memoria de la izquierda chilena. Tomo 1 (18501970). Santiago: Javier Vergara Editor, 2003.

- Baeza Bernales, Javier, Cooperativas de Pequeños Agricultores. Santiago: Memoria de prueba para optar al grade de Licenciado de la Facultad de Ciencias Jurídicas y Sociales de la Universidad de Chile, 1940.

- Bowen, Alfredo, Ensayo sobre el movimiento sindical y el sindicalismo agrícola. Santiago: s/e, 1933.

- Caja de Colonización Agrícola, La Ley $\mathrm{N}^{\circ} 4.464$ y su reglamento. Santiago: Impr. Nacional, 1929.

- Chacón, Juan, El problema agrario y el Partido Comunista, informe presentado ante el XI Congreso Nacional del Partido Comunista de Chile, celebrado en Santiago de 
Chile los días 19 al 25 de diciembre de 1939. Santiago: Ediciones del Comité Central del Partido Comunista de Chile, 1940.

- Chaparro, Leoncio, Colonización y Reforma Agraria: Hacia una distribución más justa de la tierra en Chile. Santiago: Imprenta Nascimento, 1932.

- Código del Trabajo con todas sus modificaciones y reglamentos. Santiago: Edición del 'Diario Oficial' Imprenta La Nación, 1934.

- Conteras Labarca, Carlos, Unidad para defender la Victoria. Santiago: Editorial Antares, 1938.

- Frei Montalva, Eduardo, Chile desconocido. Santiago: Editorial Ercilla, 1937.

- Garcés, Mario, Movimiento obrero en la década del treinta y el Frente Popular. Santiago: Tesis de Licenciatura, Universidad Católica, 1985.

- _______________ El despertar de la sociedad. los movimientos sociales en América Latina y Chile. Santiago: LOM Ediciones, 2013.

- García Linera, Álvaro, La potencia plebeya. Acción colectiva e identidades indígenas, obreras y populares en Bolivia. Buenos Aires: FLACSO Co ediciones y Prometeo Libros, 2008.

- Garrido, José (Ed.), Guerrero, Cristian y Valdés, María Soledad, Historia de la Reforma Agraria en Chile. Santiago: Editorial Universitaria, 1988.

- Grez, Sergio, Historia del comunismo en Chile. La era de Recabarren (1912-1924). Santiago: LOM Ediciones, 2011.

- Illanes, María Angélica, "La cuestión Campesina y el Frente Popular, 1936-1940”, Santiago: Informe de Trabajo, Universidad ARCIS, 2004, Inédito.

- _______________ "En los caminos de la patria. El desalojo campesino como castigo político patronal. Chile, 1938-1947”, Santiago: 2014, Inédito.

- Lizama, Carlos, La sindicalización campesina. Santiago: Imprenta Sur, 1939.

- Loveman, Brian, El mito de la marginalidad: participación y represión del campesinado. Santiago: ICIRA, 1971.

- ______________, Antecedentes para el estudio del movimiento campesino chileno: pliegos de peticiones, huelgas y sindicatos agrícolas, 1932-1966 Vol. I- II. Santiago: ICIRA, 1971.

- _ _ _ 1919-1973. Bloomington: University of Indiana Press, 1976.

- Loveman, Brian y Lira, Elizabeth, Las ardientes cenizas del olvido: Vía chilena de Reconciliación Política 1932-1994. Santiago: LOM Ediciones, 2000.

- ________________ Poder Judicial y conflictos políticos (Chile: 1925-1958). Santiago: LOM Ediciones, 2014.

- Lowy, Michael, El Marxismo en América Latina. Santiago: LOM Ediciones, 2007. 
- Merlucci, Alberto, Acción colectiva, vida cotidiana y democracia. Ciudad de México: El Colegio de México, 1999.

- Milos, Pedro, Frente Popular en Chile. Su configuración: 1935-1938. Santiago: LOM Ediciones, 2008.

- Moulián, Tomás, Fracturas. De Pedro Aguirre Cerda a Salvador Allende (19381973). Santiago: LOM Ediciones, 2006.

- Partido Socialista, Grove, el militar y el ciudadano. Santiago: Secretaria Nacional de Cultura y Propaganda, 1937.

- Partido Socialista de los Trabajadores, El Camino del Pueblo. Resoluciones del Tercer Congreso General del Partido Socialista de Trabajadores, Santiago, $1^{\circ}$ al 3 de Mayo de 1942. Santiago: Ediciones Combate, 1942.

- Primer Congreso de Obreros Agrícolas, inquilinos y medieros, celebrado en Santiago los días 4,5, y 6 de septiembre de 1942. Santiago: Impresora El Mundo, 1942.

- Salazar, Gabriel, Los movimientos sociales en Chile. Trayectoria histórica y proyección política. Santiago: Uqbar Editores, 2012.

- Santa Cruz, Gonzalo, El mejoramiento de los trabajadores agrícolas y la sindicalización campesina. Santiago: Memoria para de prueba para optar al grado de licenciado en la Facultad de Ciencias Jurídicas y Sociales de la Universidad de Chile, 1941.

- José Stalin, Fundamentos del Leninismo. Santiago: Editorial Antares, 1938.

- Tarrow, Sydney, El poder en movimiento. Los movimientos sociales, acción colectiva y la política. Madrid: Alianza Editorial, 1998.

- Valenzuela, Humberto, Historia del Movimiento Obrero. Santiago: Quimantú, 2010.

- Wolf, Eric, Las luchas campesinas del siglo XX. Ciudad de México: Editorial Siglo XXI, 1999.

- Zibechi, Raúl, Autonomía y emancipaciones. América Latina en movimiento. Santiago: Editorial Quimantú, Santiago, 2008.

Agradecimientos a quienes me facilitaron material o me dieron sugerencias y correcciones: Brian Loveman, Víctor Muñoz, Renzo Henríquez, Camilo Plaza, Daniela Luque, en especial a María Angélica Illanes. 